\title{
التقابل اللغوي بين اللغة العربية و الإنجليزية
}

\author{
ذو الفكر بن مئمَّم
}

\section{مدرس قسم تدريس اللغة العربية في الجحامعة الإسلامية الحكومية بنجكولو \\ (البريد الإلكتروين: (zulfikri.m73@gmail.com)}

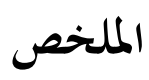

\begin{abstract}
Although Arabic and English comes from a different clumps, Arabic is included in the Semitic language family and still related to the Hebrew language, while English is included in Germanic or better known as Anglo Saxons, but there are also points of similarity between Arabic and English. The comparison between Arabic and English is more famous in the world and interested to discuss in order to facilitate Language Learning. In this article the author discusses the similarities and differences between Arabic and English in terms of pattern or structure of sentence formation.
\end{abstract}

Keywords: Comparison, Arabic, English

والاختلاف بـين اللغـات، بهـدف التنبؤ

بالصعوبات الستي يتوقـع أن يواجهرــا

التقابـل اللغوي هـو إجـراء دراسـة

الدارسون عند تعلمهم لغة أجنبية. وهذا

يقارن فيها الباحث بين لغتين أو أكثر،

بالتـالي يسـاعد في عـدة أمسور؛ منهـا:

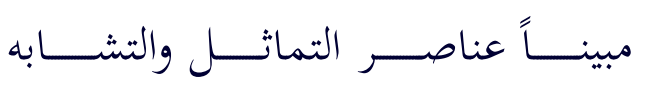


استكشـافيّة. 2 وكانـت لكل لغـة أنظمـة

وخصـائص وميزات مـن جميع النواحي

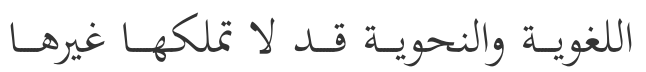

$$
\text { وبتعلها تختلف عن الأخرى. }
$$

ومـن المعلـوم أن اللغــة العربيـة و

الإنجليزية هما من أكثر اللغات انتشاراً في

العـالم, ولا شـك أن هنـاك أوجـه تشـابه

واختلاف بينهما. هذا المقال يهدف إلى

التعـرف على تلـك الأوجــه ( أوجــه

التشــابه والاخـتـلاف ) بــين اللغتــين.

ولكني أحسد الكـلام عنهـا على أوجـه

التشـابه والاخستلاف بينهمــــ في نظـام

الجملة فقط حيث سأعالج هنـا وصف

نظـام الجملـة في اللغتـين, ثم بيـان اوجـهـ

التشـابه والاخـتلاف بينهمــا في ذلـك

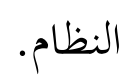

عبد العليم إبراهيم , الموجه الفني لمدرسي اللغة 2

العربية , (القاهرة: دار المعارف) ط.8. ص.43
تأليف الكتب والمواد التعليمية المناسبة، وإعـــداد الاختبــارات اللغويــة المناســبة أيضـاً. وغير ذلك من المجالات العملية التعليمية. 1

واللغـة نفسـها هـي أداة الاتصـال بين مجموعـة مسن البشر ووسيلة التفـاهم بينهم. وبعبارة أخرى, إن اللغة هي نسقُ من الرموز والإشارات وأداة من الأدوات الـتي يعسبّر بهــا الفــرد عـنـ المشـــاعر

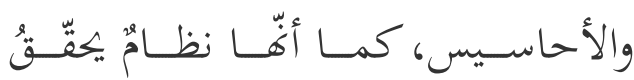
وظـائفَ معرفيّة ووظـائف تواصليّة بـين البشر، وتعدّ من الظواهر السلوكيّة، ومن وظائفهـا: الوظيفــة الاجتماعيّة، وظيفــة التعبـير، ووظيفــة الاسـتدعاء، والوظيفـة النفسـيّة، ووظيفــة تفاعليّـة، والوظيفيـة الفكريّة، والوظيفة الشخصيّة، والوظيفـة التخيليّــة، ووظيفـــة تنظيميّــة، وظيفــة

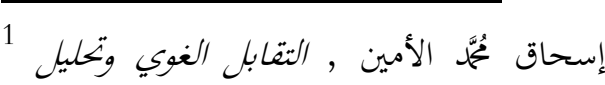

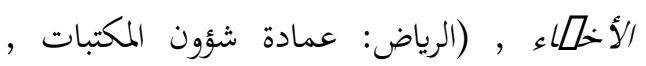
جامعة الملك سعود, 1982) ط.1. ص.هـ 
النظام اللغوي عند العرب" آراء

العلمـــاء القـــدماء والمحــــثن في

الجملـة وتقسـيماتم هـا: فـالمبرد

يقســـــها إلى قســـمين اسميـــة

وفعليـة. أمـا الزخشــري فقسـمها

إلى أربعـة أقســام الميــة وفعليـة

وظرفيـة وشـرطية. وكـان رأي ابن

هشـام ومـن تبعـه مثـل السـيوطي

أهــا ثلاثـة أقســام اسميـة وفعليـة

وظرفية وتابعه على ذلك مهدي

المخزومي من العلماء المحدثين.

واقتصــرت كثـــير مـــن

الشـروح النحويـة عنــــــــر مـن

العلماء المحدثين في تقسيم الجملة

في اللغــة العربيـة على قســمين

إسميـة وفعليـة وعلى هـذا سـوف

أســير في تحليلــي للجملـــة في

العربيـة ولأن هـذا هـو المقابـل لـا

دز عبدالمجيد عيساني, جامعة قاصدي مرباح 4

ورقلة, الجمملة في النظام اللغوي عند العرب
أ. وصف نظام الجملة في اللغتين:

1. نظام الجملة في اللغة العربية:

يعرّف ابن هشام الجملة )

أو الكـلام ) بإهــا عبـارة عمــا

اجتمـــع فيـــه أمـــران: اللفـــ

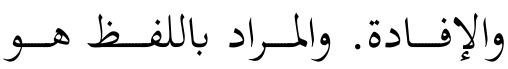

الصــوت المشــتمل على بعـض

الحروف تحقيقـا أو تقديرا. والمراد

بالإفــادة مــا دل علـى ووعـنى

يحسن السكوت عليه.

أمـا في تقسـيم الجملــة في

اللغة العربية فقد اختلف العلماء

في القديم والحديث عنها, وذلك

بسـبب إخـتلاف تفسيرهم لهـا.

فتــــد أورد الــدكتور عبدالمجيـــد

عيســاني في بكثــــه "الجملــــة في

ابن هشام, أوضح المسالك إلى ألفية /بن مالك, 3

(القاهرة : دار الفكر) ط.1, ص. 11 
يمكنه أن يحمل إعرابه أو في محل

إعرابـهـ. والخــبر يكـــون مفــرد

ويكــون جملــة اسميـة أو فعليـة

فتكـون الجملـة الاسميـة كمـا في

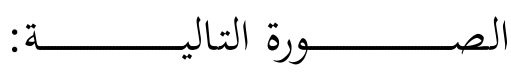

يسـمى جملـة باللغـة الإنجليزيـة

-sentence

فالجملة الاسمية: هي كل

جملة صدرها اسم. فتتكون من

مبتدأ وخبر وصدرها المبتدأ وهو

إسم وقد ينوب عنه في مكانه ما

\begin{tabular}{|c|c|c|}
\hline المثال & التشكيل & الرقم \\
\hline - العلم نور والجهل ظلام - الإنسان مدلي باللابع & اسم + اسم & 1 \\
\hline - - الصحة مفتاحها النظافة مرتعه وخيم & اسم + جملة اسمية & 2 \\
\hline - الصبر يعين على كل شيء & اسم + جملة فعلية & 3 \\
\hline
\end{tabular}

أما الجملة الفعلية: فهي كل جملة صدرها فعل ويليه فاعل وقد يليه مفعول أو أكثر. فتكون الجملة الفعلية كما تلي:

\begin{tabular}{|l|l|l|}
\hline الرقم & المثال \\
\hline
\end{tabular}




\begin{tabular}{|c|c|c|}
\hline - - رسب اللالب - حدث الانفجار & فعل + فاعل & 1 \\
\hline - - راجع اللالب دروسه & فعل + فاعل + مفعول & 2 \\
\hline
\end{tabular}

2. نظام الجملة في اللغة الإنجليزية:

أمـا في اللغة الإنجليزيـة فأجزاء الجملـة الاساسية فيها هي الفاعل والفعل حيـث غالبـا مـا يكـون الفاعل علمر, والفعل (المسـند) غالبـا مـا يتبع الفاعـل ويصف حدث أو موقف ما. فتكون جملة فعلية فقط على النحو التالي:

\begin{tabular}{|c|c|c|}
\hline المثال & التشكيل & الرقم \\
\hline $\begin{array}{l}\text { I get up at } 4.30 \text { every morning } \\
\text { We talked at the coffee shop }\end{array}$ & فاعل + فعل & 1 \\
\hline $\begin{array}{l}\text { My wife wears hijab whenever she is going out } \\
\text { I always wash my face before sleeping }\end{array}$ & فاعل + فعل + & 2 \\
\hline
\end{tabular}

و لا توجد جملة اسمية في اللغة الإنجليزية حيث لابد أن يكون هناك فعل في الجملة لكي تكون صحيحة نحويا. لذلك أوجدوا ما يسمى بالافعال الرابلهة أو الافعال المساعدة (is-are-was-were) فتكون الجملة: 


\begin{tabular}{|c|c|}
\hline فاعل & التشكيل \\
\hline He is a lawyer & \\
We are all kind & خعل رابط \\
\hline
\end{tabular}

الجملـة الجملة الفعليـة الانجليزيـة

مع الجملـة الاسميـة العربيـة لـولا

وجود تلك الافعال الرابلة.

فمثلاً جملة "My father

is a teacher

هي " أبي هو مدرس " لكن

في العربية يقال " أبي مدرس "

فقــط لوجـود صـيغة الجملــة

$$
\text { الاسمية في العربية. }
$$

وأمر آخر يجعل الجملتين

متلـابقتين هو أن " is " " في

اللغة الانجليزية يعتبر فعل رابط

معنــاه يـوازي اســم الاشــارة
ب. أوجه التشابه بين نظام الجملة في اللغة العربية واللغة الانجليزية:

تتشابه الجملة في اللغة العربية

وفي اللغــة الانجليزيـة في ناحيتـين

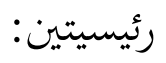

1. على الرغم من عدم وجود جملة

اسميـة في اللغـة الانجليزيـة الا أن

هناك جملة تشبه الجملة الاسمية

في اللغة العربية, الا وهي الجملة

الفعليـة ذات الافعـال الرابلــة أو

is-are-was-" الافعال المساعدة

were 
تختلــف الجملـــة في اللغــة

العربية عنها في اللغة الانجليزية في

ناحيتين رئيسيتين:

1. الجملة الاسميـة في اللغة العربيـة

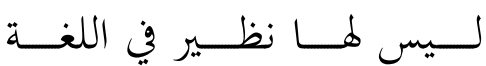

الانجليزية حيث لا توجد جملة

اسميــة في اللغــة الانجليزيـة لان

كل جملها تحتوي على افعال.

2. الجملـة الفعليـة في اللغـة العربيـة

يختلــف ترتيبهـا عـن ترتيـب

الجملــــة الفعليــــة في اللغــــة

الانجليزيـة حيـث صـدر الجملـة

الفعليـة في اللغــة العربيــة هـو

الفعـل ويليـهـ الفاعـل ويليـهـ

المفعول. أمـا في اللغة الانجليزية

فإن الجملة الفعلية تبدأ بالاسم

و يليه الفعل ثم المفعول. فوجها

الاخــتلاف يكــون في تبــادل

الترتيـب بـين الاسـم والفعـل في

الجملة الفعلية في اللغتين.
باللغة العربية "هو , هي" الذي

يعتـبر مـن الاسمــاء فحـــث

الاخستلاف في الاعـراب بـين

اللغتـين والتسـمية كـذلك مـع

وجود أسمـاء الاشـارة في اللغـة

الانجليزية.

2. ووجه التشابه الآخر بين الجملة

الفعليـة في اللغـة العريـة والجملـة

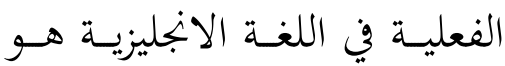

تشـــابه الملكــــونات الرئيســـية

للجملتسين حيـث يكـوي كـلِ

منهما فعل وفاعل. مثنلا " أكل

مُعْمَّم التفاحسة " فعـل وفاعـل

ومفعول به " Mohammad ate

" the appel

ومنعول به.

ج. أوجه الاختلاف بين نظام الجملة في اللغة العربية و الانجليزية. 
لنا أن نقول إن الجملة في اللغة الانجليزية

هي نفسـها في اللغـة العربيـة لـولا تقـديم الفاعل على الفعل واشتراط وجود فعل أو فعل رابط " اسم إشـارة " للجمل ل الإسمية.

اذًا يجــب أن نركز في التحبيقـات على موضع الفعل قبل الفاعل في الجملة الفعلية و نركز على التأكيد على حذف اســم الاشـارة بعــــ المبتـــأ في الجمملـة . الأسمي

الملكتبات , جامعة المللك سعود,

$(1982$

$$
\text { أنلاوان الدحداح, معجم قواعد اللغة }
$$
العبية في جادول ولوحات , لبنان عبد العليم إبراهيم , الموجه الغني لملسرسي

$$
\text { اللغة العربية , (القاهرة: دار المعارف) }
$$

مـا مـر اتضـح لنـا أوجـه التشـابه والاختلاف في نظام الجملة بين اللغتين

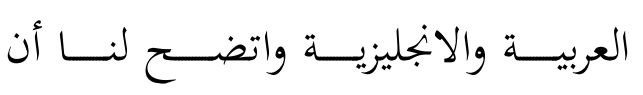
الاخـتلاف الرئيسي يكمـن في التسـمية والوظيفـة التي علقـت على بعض أجـزاء الكــام في اللغتـين حيـث كـون اسـم الاشـارة "هـ وهي" في اللغة العربية هــا المقابل للفعل الرابط "is " واسم الاشارة " He, She " ابن هشام, أوضح المسالك إلى ألغية ابن مالك, (القاهرة : دار الفكر) إسحاق تُحَّمَ الأمين , التقابل الغوي وتحليل الأخلاء , (الرياض: عمادة شؤون 